
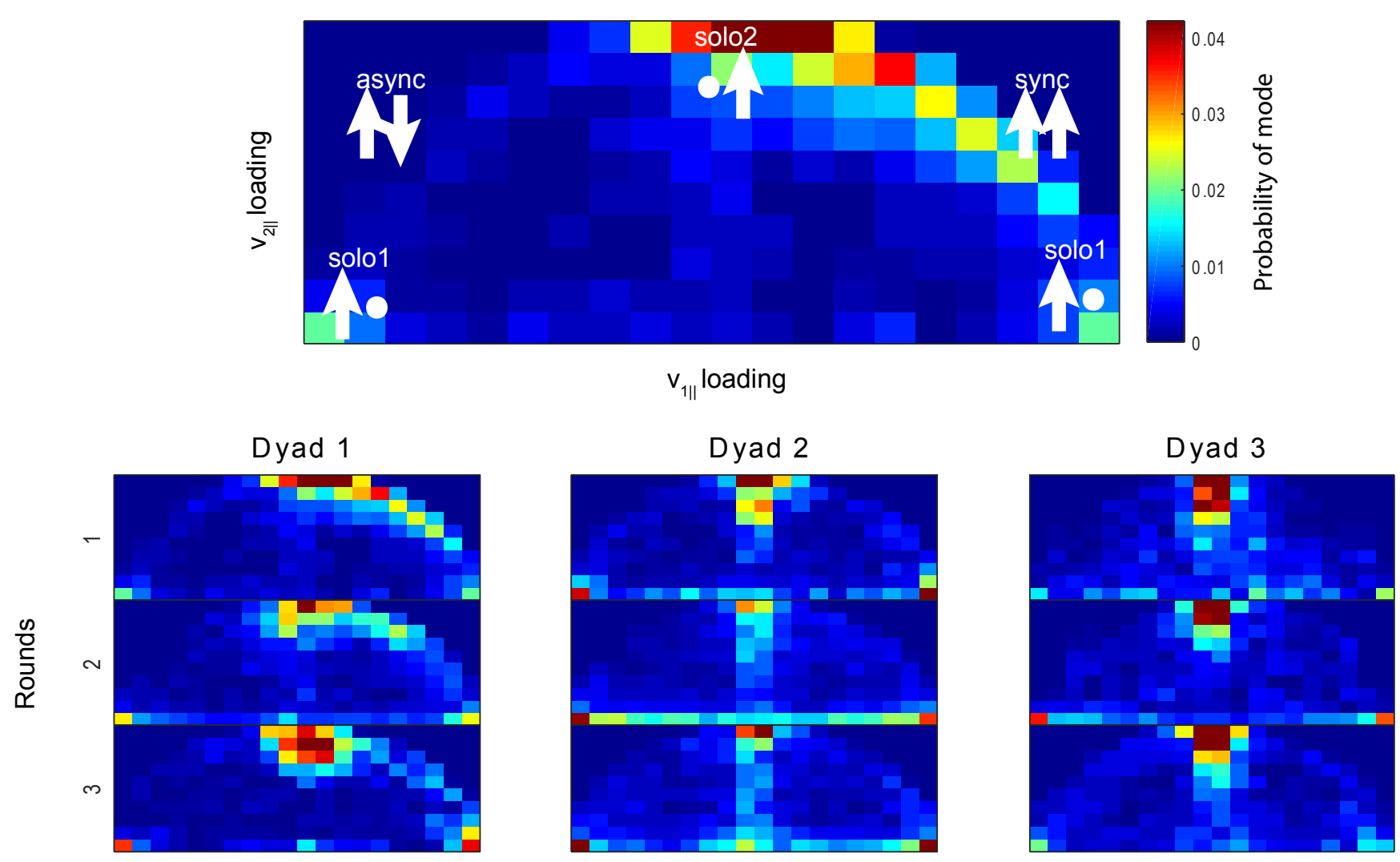

\title{
Dyad 5
}

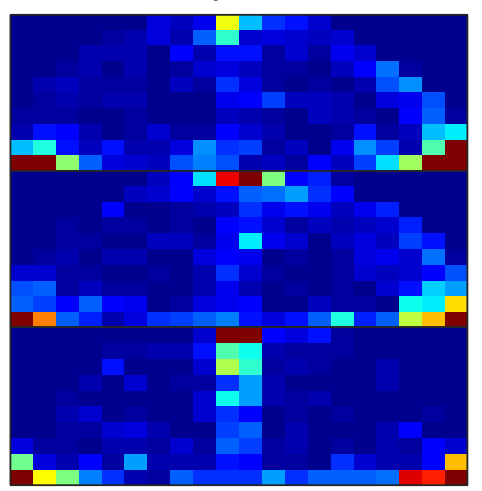

\section{Dyad 7}

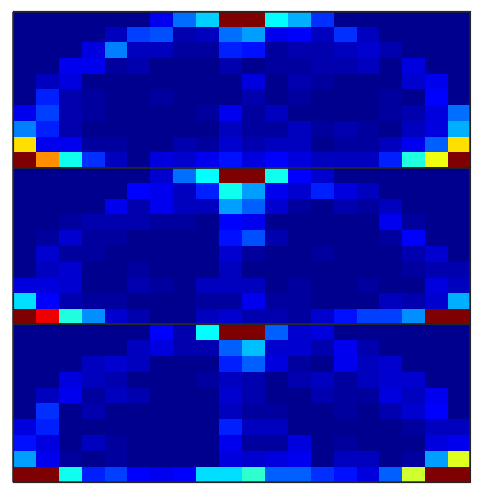

\section{Dyad 4}

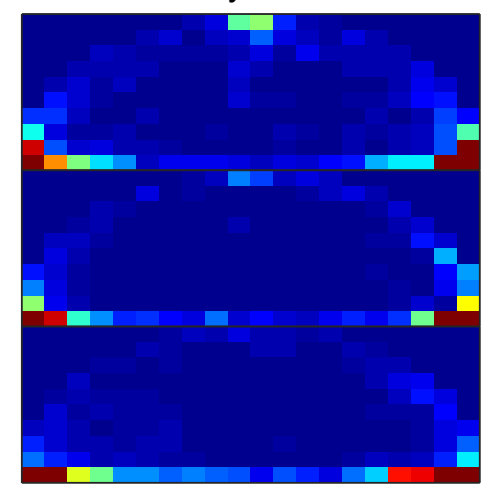

Dyad 10

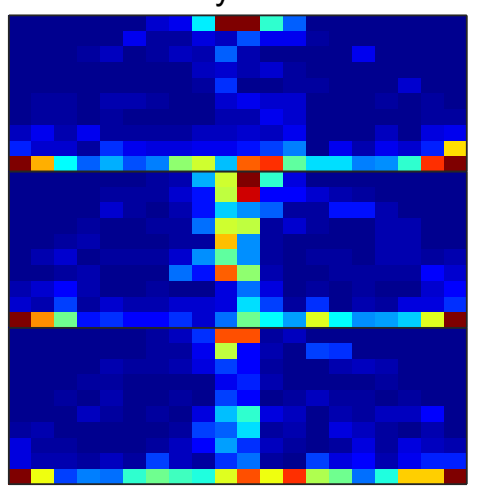

\section{Dyad 8}

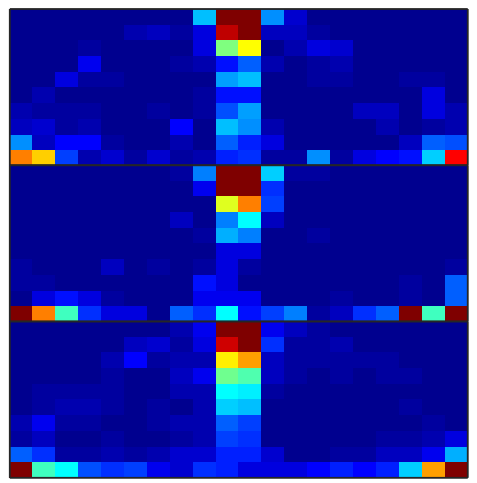

$+$

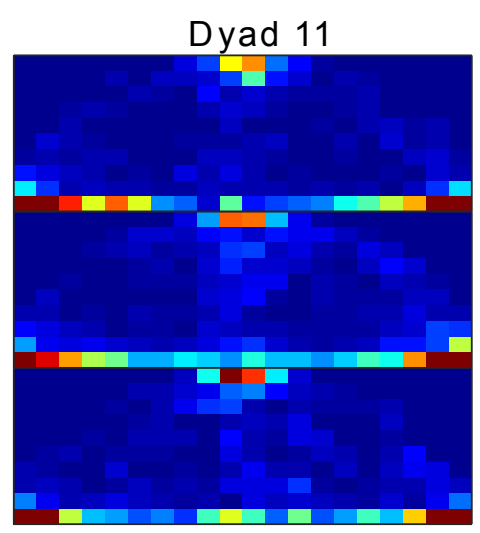

\section{Dyad 9}

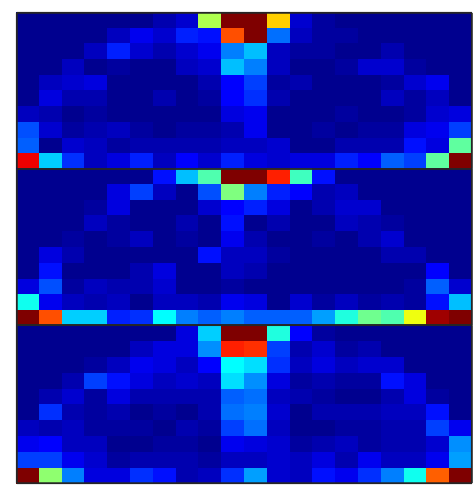

Dyad 6

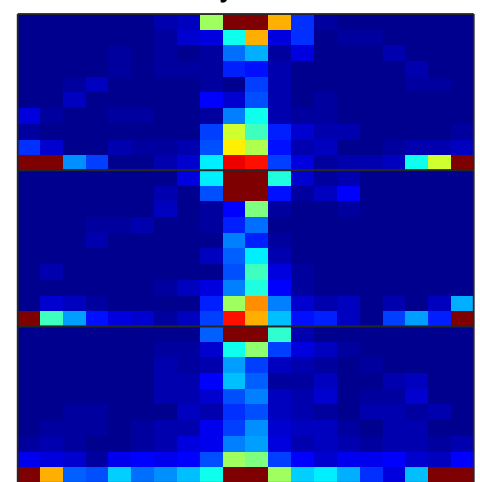

Dyad 12

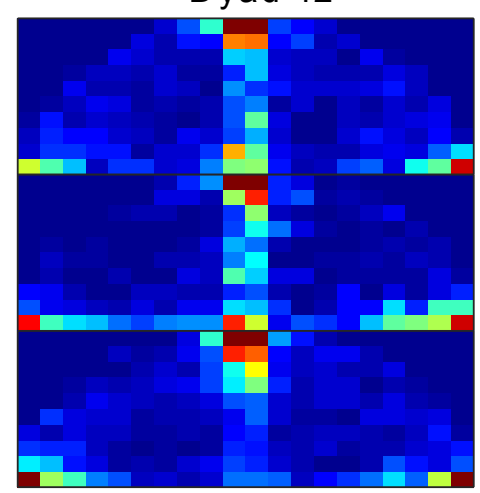

